\title{
前進速度を有する小アスペクト比振動平板翼 に作用する流体力について
}

\author{
正員 湯 浅 和 昭* 正員 藤 野 正 隆 ${ }^{* *}$ \\ 正員 元 良 誠 三**
}

New Approach to Hydrodynamic Forces on Oscillating Low Aspect Ratio Wings

by Kazuaki Yuasa, Member

Masataka Fujino, Member

Seizo Motora, Member

Summary

A new approach to calculating the hydrodynamic forces acting on harmonically oscillating low aspect ratio wings is presented. This approach is based on free streamline theory and lifting surface theory. The hydrodynamic forces can be represented by a linear combination of the inertia force, the first order damping force, that is to say "lift", and the second order damping force, that is to say "drag". Each component of these forces estimated by the model of lifting surface with free stream is compared with the experimental results obtained by the forced oscillation of rectangular low aspect ratio wings. And chordwise pressure distribution estimated by the model is compared with that of measurement.

As the results of these comparisons, the following conculsions are derived:

1) Although the equivalent total drag coefficient, $C_{d t}$, of estimation increases monotonously with the inverse of reduced frequency, that of experiment is not so much varied with reduced frequency, $k$, for fixed period parameter, P.P., and aspect ratio, A.R. In the range of small $1 / k$ the experimental $C_{d t}$ becomes less than that at the time when $1 / k$ equals to zero.

2) The result of the chordwise pressure distribution shows that as $1 / k$ increases drag forces decrease and lift forces increase, so $C_{d t}$ is not so much varied then.

3) The added inertia coefficient, $C_{m}$, of experiment is remarkably dependent on $k$ however, that of estimation is close to 1.0 and less dependent on $k$ in low aspect ratio wings. In the range of small $1 / k$ experimental $C_{m}$ is much greater than 1.0 and it becomes close at estimated $C_{m}$ as $1 / k$ increases.

\section{1 緒言}

船体にはビルジキール・フィンスタビライザ・舵など アスペクト比の比較的小さな翼が付いており，船体自身 を小アスペクト比の翼として考学る場合もある。特に横 摇に関するビルジキール・アンチローリングフィンの減 衰効果を考える場合, 小アスペクト比平板翼の振動問題 を考えることは非常に重要な課題であり, しかも, 純粋 に流体力学的京意味からも興味深い問題である。

ビルジキールの減摇効果に関する研究は古くから行な われて拉り，奏用的な実験式も発表されている11，また， 最近ストリップ法的な観点に立った研究が精力的に進め

* 三菱重工業(株)船舶技術部総合計画課

** 東京大学工学部船舶工学科

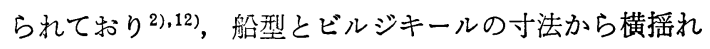
減衰係数を求める実用的な方法が完成されるのも，そう 遠い将来でないように思われる。

だが、これまでの研究を見ると、ビルジキールは, 前 進速度のない振動平板として取扱われている場合が多く 前進速度をるつ小アスペクト比の振動翼として取扱った 例は少ないように思われるので, 本論文では, 前進速度 のある場合のビルジキールの効果を検討するための基礎 として, ビルジキールの運動する半径はビルジキールの 深さに比べて十分大きいことを考慮にいれて, 前進方向 に直角に調和運動をしつつ前進する小アスペクト比平板 翼に加わる流体力を考えてみることにした。

このように単純化された振動平板に加わる流体力を本 論文では，次のような順序で考察する。 
i ）流体力の評価方法

流体力は, 付加慣性力, 振動平板としてのいわゆる抗 力 (2 次の減衰力) と, 前進速度がある時に作用する揚 力（振動翼としての 1 次の減衰力）の 3 つの成分から成 ると考える。

ii）流体力のモデル化

i ）で述べた流体力の具体的評洒方法として，「揚力 面理論」十「(cross flow 成分に対して) 死水モデル」の 重ね合わせモデルを考えることにした。

iii） 流体力・コード方向圧力分布実験および流れの 様相観察

ii）の流体力のモデルの妥当性と問題点を明らかにす るために行なった実験結果について検討する。

なお，本論文中で使用される変数の定義は下記のと拈 りである。

$U:$ 一様前進速度

$\omega$ : 振動周波数

$b$ : 翼幅

$l:$ コード長

$\rho:$ 流体の密度

$k$ : reduced frequency $(=\omega l / 2 U)$

A.R. : アスペクト比 $(=b / l)$

$\nabla:$ 直径 $b$, 長さ $l$ の円筒の体積 $\left(=\pi b^{2} l / 4\right)$

$S:$ 翼面積 $(=b l)$

$C_{m}:$ 付加質量係数

$C_{d}:$ 抗力係数

$C_{L \alpha}:$ 揚力係数

$C_{d t}$ : 等価全抗力俰数 $\left(=C_{d}+\frac{3 \pi}{16} \frac{b}{a} \frac{l}{b} \frac{2 U}{\omega l} C_{L \alpha}\right)$

$L$ :揚力

$d L / d x:$ コード方向揚力分布

$d L / d s:$ 圧力分布 $(d s=d x d y)$

$\boldsymbol{a}:$ 振動振幅

$\nu:$ 流体の動粘性係数

$\beta$ : 最大流入角

$h$ : Riabouchinsky model の二平板間隔

P.P. : Period Parameter $\left(=|\dot{z}|_{\max } T / b=2 \pi \frac{a}{b}\right)$

$R_{n}:$ Reynolds 数 $\left(=U l / \nu\right.$ or $\left.|\dot{\boldsymbol{z}}|_{\max } b / \nu\right)$

$R_{a}:$ 翼面

$R_{w}:$ 自由渦面

$R_{r}:$ 翼面および自由渦面以外の領域

\section{2 流体力の評価方法}

前進速度Uを持つ流れの中で微小振動する翼に作用す る流体力を取り扱う揚力面理論においては，流体力を付 加慣性力と揚力に起因する減衰力との和として,

$$
F=C_{m} \rho \nabla \ddot{z}+\frac{1}{2} C_{L \alpha} \rho S U \dot{z}
$$

のごとく考えている。これは, 自由渦面が trailing edge より流出し翼面の一様方向に対する投影面と同一平面上 に存在していると仮定し, Euler の運陲方程式における 靦乱速度が一様流速に比べて $O(\varepsilon)$ であることを利用し て，その 2 次以上の項を省略することにより導かれた。 つまり, trailing edge および tip から流出する自由渦 の変形を考慮にいれていない。

一方，一様に斜航する船体に却わる学流体力を取扱 う問題においては，浜本 ${ }^{4)}$ は Bollay にならって自由洞 層を流出させた場合の一般式を導き，野中5) は流れの钼 察から渦核を形成する自由渦面を敒定して流体力の計算 を行なっている。しかし，自由渦が運動している振動問 題にこれらの方法を直接拡張するのは困難であろら。ま た，貴島 ${ }^{6)}$ は Bollay 流の考方方から準定常的に自由渦 の変形をも考慮に入れて船体が yawing する時の流体力 を小アスペクト比振動翼と考㝋て計算しているが，準定 常な解法であるために，付加慣性力については何の考察 も与えていない。Lawrence は，一定の迎角で定常䐠が 翼にあたる場合について， cross flow による抗力成分

$$
2 \alpha^{2} \text { ( } \alpha \text { は迎角) }
$$

を，揚力係数に加えるべきであるとしているな゙，このこ とは，振動平板翼に関しても árag に刘灾する流体力を 考慮に入れるべきであることな゙示していると思われる。

また, $\mathrm{Shih}^{3}$ らの 2 次元层動平板に対する実験によれ ば, アスペクト比 0.1 の時に end plate の効果はほと んど関係なく， end plate を付けても付けなくても流体 力はほとんど変わらないといら結果が得られた。従っ て, 抗力の考劣は振動翼の tip から流出する自由渦の影 響を表わしていると考えてもよさそらである。

以上の議論から, 前進速度を有する小アスペクト比振 動平板翼に作用する流体力を

$$
F=C_{m} \rho \nabla \ddot{z}+\frac{1}{2} C_{L \alpha} \rho S U \dot{z}+\frac{1}{2} C_{C} Q S \dot{z}_{i}^{\prime} \dot{z} \mid
$$

のごとく，付加慣性力・揚力・沉力の 3 成分からなると 考克る。（3）式の右辺の各項関する具体的検討に入 る前に, 平板翼に加わる流体力を整理する無次元パラメ ーターについても若干考察しておく。なお（3）式の第 3 項は定常流に拈ける抗力とは異なるが，便宜上抗力と 呼ぶことにする。

流体力 $(F)$ は, 前進速度 $(U)$. 振動周波数 $(\omega)$ ・ 振動振幅 $(a)$ ・矩形平板翼のコード長さ $(l)$ ・矩形平 板翼のスパン長さ $(b) \cdot$ 流体の密度 $(\rho) \cdot$ 流体の動粘

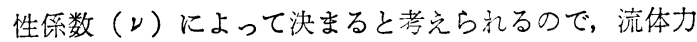
$F$ は $\alpha \sim \eta$ を末知数として

$$
F=K \cdot U^{\alpha} \cdot a^{\beta} \cdot \omega^{\gamma} \cdot l^{\delta} \cdot b^{\varepsilon} \cdot \beta^{\zeta} \cdot \nu^{\eta}
$$

と表わせると仮定し，基本単位である質量 $[M] \cdot$ 長さ $[L]$ ・時間 $[T]$ を用いて左右両辺を具体的に表示し， 
赤知数 $\alpha \sim \eta の$ 間に成り立つべき関係を求めると最終的 に流体力は,

$$
\frac{F}{\frac{1}{2} \rho U^{2} l b}=f\left(\frac{\omega l}{U}, \frac{a}{b}, \frac{b}{l}, \frac{U l}{\nu}\right)
$$

のごとく, 次の 4 つの無次元パラメータで表わされる。 reduced frequency $k=\omega l / 2 U$ period parameter P.P. $=2 \pi a / b$ アスペクト比 Reynolds 数

$$
\begin{aligned}
\text { A. R. } & =b / l \\
R_{n} & =U l / \nu
\end{aligned}
$$

なお, period parameter $(2 \pi a / b)$ は, 流れの非定常 性を表わす, いわゆる Strouhal 数 $\left(N_{s t}\right)$ の逆数であ り，振動物体の流体力を整理するのによく用いられてい る。ただし, 以下に拈いては, Martin のビルジキールに 対する実験式の表示法 $\left.{ }^{8}\right)$ に従い, period parameter $(2 \pi$ $a / b)$ の代わりに $a / b$ で実験を整理する。

ところで, $R_{n}$ については振動平板に関する Shih・ Buchanan の報告によれば, $R_{n}>250$ ならば抗力倸数 $C_{d}$ は $R_{n}$ によらないという結論が得られている。この ことを考慮に入れて, 本研究に拈いては $R_{n}>1000$ とし て実験を行ない，流体力に対する $R_{n}$ の影響はないるの と考える。

\section{3 流体力のモデル化}

\section{一死水を伴う揚力面モデル—}

小アスペクト比振動平板翼に作用する流体力を計算す るには, 微小摼乱を仮定した揚力面理論だけでは不十分 であり, cross flow に対する抗力の成分を加える必要 があることはすでに述べた。そこで，本諭文に拉いて は，抗力について死水モデルを応用することにより， Fig. 1 に示すよらな死水を伴ら揚力面モデルを考え, 流 体力を推定することを試みた。

1） $C_{d}$ の推定一一非定常運動に対する Riabouchinsky モデルの応用一

振動平板に対する抗力係数 $C_{d}$ が定常流との場合と異 なり，かなり大きな值を持つこと，执よびその值が Strauhal 数によって変わることは, Keulegan ら ${ }^{10)}$ によ って指摘されている。そこで Riabouchinsky の死水 model を応用し, Strauhal 数によって死水の大ささが 変わり, 従って $C_{d}$ が変化すると考えてみる。

Riabouchinsky9) によれば, 平板背後の死水領域の長

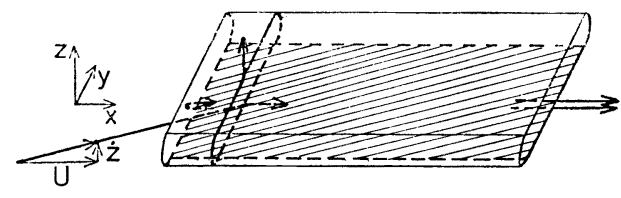

Fig.1 Conception of Lifting Surface Theory with Free Stream
さ $h$ と板幅 $b$ との比を $h / b$ とするとき, 抗力係数 $C_{d}$ は， $\alpha$ を媒介変数として次式で与えられる。

$$
\begin{aligned}
\frac{h}{3} & =\frac{E(\cos \alpha)-\sin ^{2} \alpha K(\cos \alpha)}{\sin ^{2} \alpha+E(\sin \alpha)-\cos ^{2} \alpha K(\sin \alpha)} \\
C_{d} & =2 \frac{1+\sin \alpha}{1-\sin \alpha} \frac{E(\sin \alpha)-\cos ^{2} \alpha K(\sin \alpha)}{\sin ^{2} \alpha+E(\sin \alpha)-\cos ^{2} \alpha K(\sin \alpha)}
\end{aligned}
$$

ただし，

$$
\begin{aligned}
& K(x)=\int_{0}^{\pi / 2} \frac{d \theta}{\sqrt{1-x^{2} \sin ^{2} \theta}} \quad(\text { 第 } 1 \text { 種完全楕円積分） } \\
& E(x)=\int_{0}^{\pi / 2} \sqrt{1-x^{2} \sin ^{2} \theta} d \theta （ \text { 第 } 2 \text { 種完全棈円積分） }
\end{aligned}
$$

$C_{d}$ の中に $h / b$ は explicit には入っていない弓j, $h / b$ を 小さくすると $C_{d}$ は増加する。そこで実験で得られた $C_{d}$ に見合った死水領域の長さを決定するために，まず，前 進速度 $U=0$ で実験を行ならが，これまでに行なわれた この種の研究のいくつかを紹介する。

Keulegan らの研究 ${ }^{10)}$ では平板を振動させる代わりに 水槽内に standing wave を作り，その節となるところ に平板をおいて流体力を計測しており，全体的にデータ のバラッキも少ない。McNown ${ }^{11)}$ は振動平板に作用す る流体力の瞬時值を用いて Riabouchinsky model を拡 張したモデルに対応させている。Shih · Buchanan は Reynolds 数 $\left(R_{n}\right)$ ・自由表面影響を調べているが，付 加慣性力を考慮に入れず流体力の最大值から抗力係数を 求めている。池田 ${ }^{12)} ら$ る付加慣性力は考慮していない。

そこで，本研究においては強制振動実験を行ない, $C_{d}, C_{m}$ を実験的に求め, Keulegan らの実験と比較す るとともに，実験值を用いて死水領域を決定する。

実験方法について, 詳しくは 4 章で述べるが, 自由表 面影響については, Shih らによれば平板の中心を $2 b$ 以上没水させればまず影響がないと報告されている。ま た, 本研究においても, 自由表面影響を調べるために矩 形断面 2 次元物体の横運動における付加質量と造波振幅 比を有限要素法によって計算してみたところ，5b 程度 没水させれば自由表面影響はないと考えて良さそうであ った。そこで, 本研究においては平板の中心を $5 b$ 以上 没水させて実験を行なうことにし，自由表面影響はない ものと考える。このようにして実験を行ない $C_{d}, C_{m}$ の 值を求め, Fig. 2, Fig. 3 に示す。これらの結果と Keulegan らの実験预よび池田らの実験式とを比較すると, i ) $C_{d}$ はほぼ一致している, ii) $C_{m}$ は standing wave を用いた Keulegan らの実験值よりも大きめになって いることがわかる。

次に, $C_{d}$ の実験值から死水領域 $(h / b)$ を決定したと ころ,

$$
\frac{h}{b}=0.263 \frac{a}{b}+0.104
$$




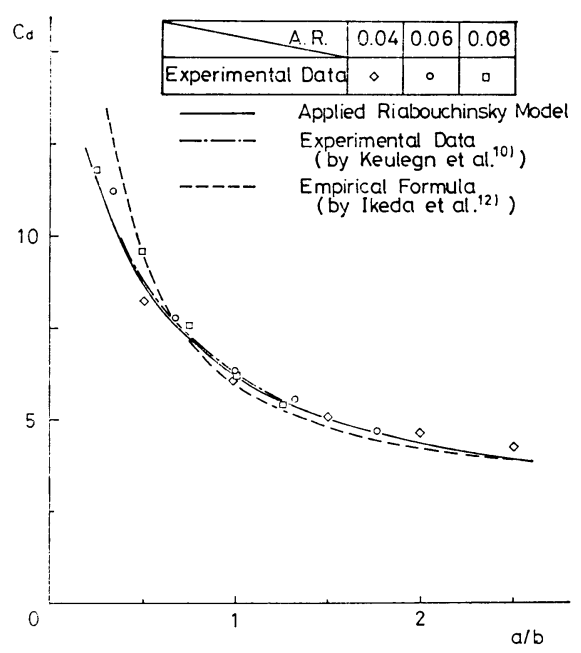

Fig. $2 C_{d}$ vs. $a / b$ Relations for $U=0 \mathrm{~m}$

とすると実験值の $C_{d}$ をよく説明できることがわかった (Fig. 2)。

2) $C_{L \alpha} \cdot C_{m}$ の推定——Lawrence の方法による計 算 ${ }^{13)}$

Reissner によって示された誘導速度に関する積分方 程式をスパン方向に重み積分して計算する方法で，Fig. 4 に示すように右手直交座標系を用いて, 主流方向に $x$ 軸・スパン方向に $y$ 軸・翼面と鉛直方向に $z$ 軸をとり, 速度ポテンシャルは一様流速Uで無次元化しておくと, 翼面上での $z$ 方向誘導速度は,

$$
\frac{\partial \phi}{\partial z}=-\frac{1}{2 \pi} \frac{\partial}{\partial y} \iint_{R_{a}+R_{w}} \frac{\frac{\partial \phi}{\partial x}}{y-\eta}\left(1+\frac{r}{x-\xi}\right) d \xi d \eta
$$

ただし，

$$
r=\sqrt{(x-\xi)^{2}+(y-\eta)^{2}}
$$

$R_{a}:$ 翼面, $R_{w}$ : 自由渦面 で与えられる。境界条件として, 無限上 流で鯢乱がなく，翼面上で翼をよぎる流 れがなく，後縁で Kutta の条件を満足 するものとする。コード方向揚力分布 は, 圧力分布をスパン方向に積分して,

$$
\begin{aligned}
\frac{d L}{d x}= & \int_{-b / 2 l}^{b / 2 l} \frac{d L}{d s} d y \int_{-b / 2 l}^{b / 2 l} \\
& \times 2 \rho U^{2}\left(\frac{\partial \phi}{\partial x}+i k \phi\right) d y
\end{aligned}
$$

として計算する。このようにして計算し た揚力分布の加速度成分および速度成分 を Fig. 5 に示す。

次に，揚力分布をコード方向に積分し て揚力の加速度 $\cdot$ 速度成分から $C_{m} \cdot C_{L a}$

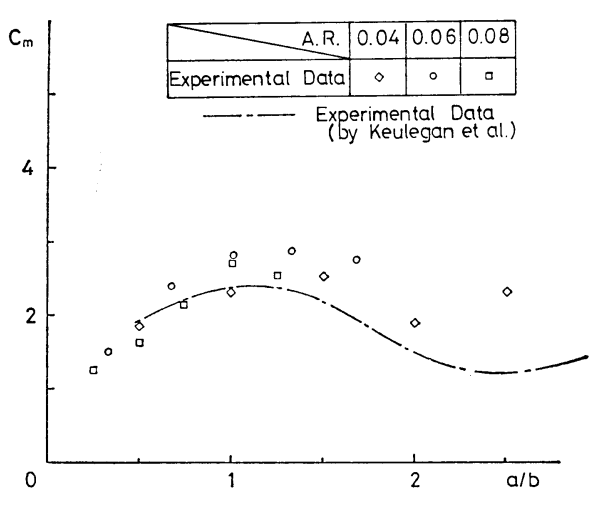

Fig. $3 C_{m}$ vs. $a / b$ Relations for $U=0 \mathrm{~m}$

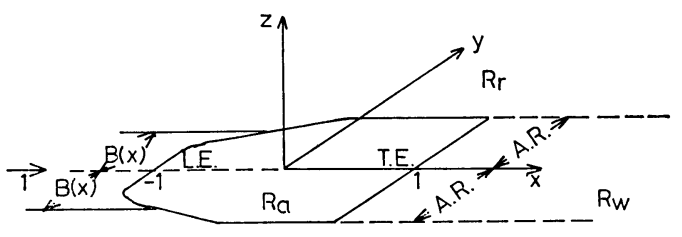

Fig. 4 Coordinate System

を求めて reduced frequency $(k)$ に対して図示したの が, Fig.6, Fig.7 である。これらのグラフから, アスペ クト比が小さい場合は, $C_{m} \cdot C_{L \alpha}$ はともに reduced frequency にほとんどよらないといえる。

そこで， $C_{L \alpha}$ は小アスペクト比平板翼の揚力の考えに 基づき,

$$
C_{L \alpha}=\frac{\pi}{2} \cdot \text { (A.R.) }
$$

とし， $C_{m}$ に関しては各アスペクト比に対してLawrence の方法で計算した值 (Fig.6) を用いる。

以上をまとめると， period parameter によって決ま る $C_{d}$ とアスペクト比の関数としての $C_{L \alpha}, C_{m}$ を使っ て, 前進速度を有する振動平板に加わる流体力を（3） 式で評価するというのが，本論文のねらいである。

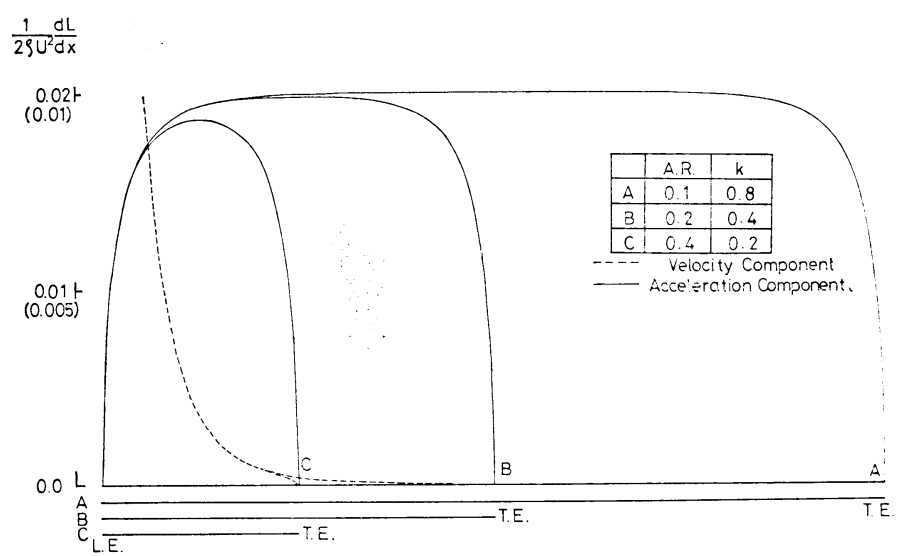

Fig. 5 Chordwise Load Distribution 


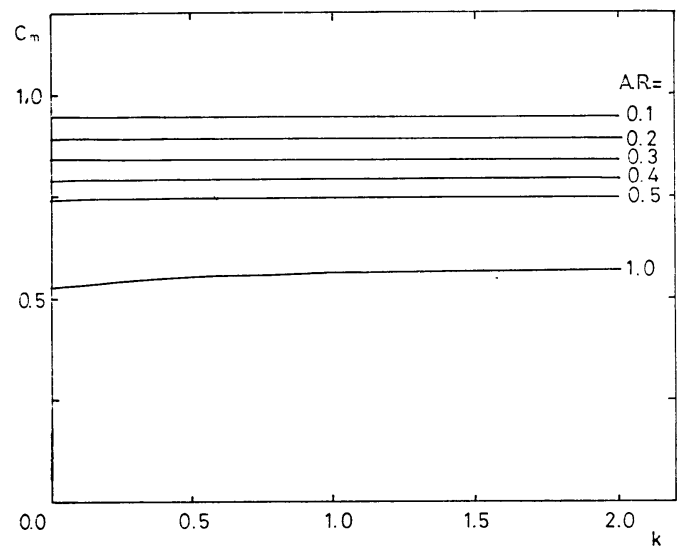

Fig. $6 C_{m}$ vs. $k$ Relations for Low Aspect Ratio Wings

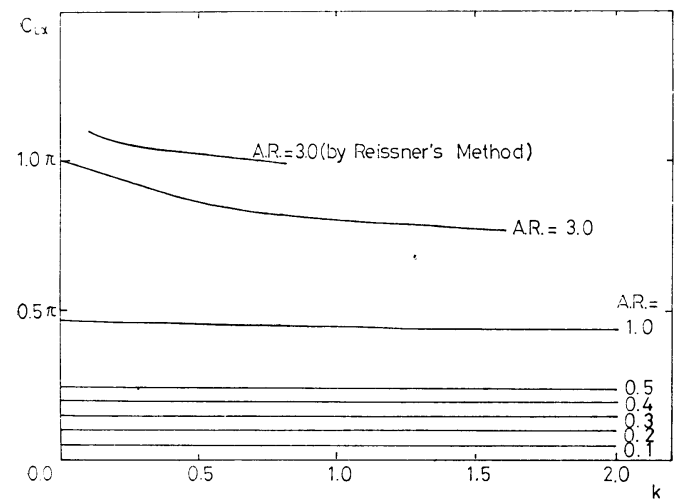

Fig. $7 C_{L \alpha}$ vs. $k$ Relations for Low Aspect Ratio Wings

\section{4 小アスペクト比振動平板翼に作用する 流体力の計測実験}

以上の推定が果して妥当であるかを調べてみるために 以下に示すような方法で実験 を行ない, 計算結果と比較し た。

1）実験方法および解析 方法

実験装置全体の概略図を Fig. 8 に示す。本装置はスコ ッチョークを用いた強制動摇 装置で, 平板を振動周期 $(T)$ で振動させながら曳航し，平 板に加わる流体力を計測する ものである。

実験に用いた平板翼の大き さおよび重量などは，Table 1 に示す。また，実験状態は
Table 1 Dimensions of Rectangular Wings

\begin{tabular}{c|c|c|c|c}
\hline \hline A.R. & $\begin{array}{c}l \\
(\mathrm{~m})\end{array}$ & $\begin{array}{c}b \\
(\mathrm{~m})\end{array}$ & $\begin{array}{c}t \\
(\mathrm{~mm})\end{array}$ & $\begin{array}{c}m \\
\left(\mathrm{~kg} \cdot \mathrm{sec}^{2} / \mathrm{m}\right)\end{array}$ \\
\hline 0.04 & 1 & 0.04 & 4 & 0.0439 \\
0.06 & 1 & 0.06 & 4 & 0.0659 \\
0.08 & 1 & 0.08 & 4 & 0.0878 \\
\hline
\end{tabular}

振幅（a）について $2.0 \sim 10.0 \mathrm{~cm}$ の間を 5 通り，周期 (T) について 1.5 5. $0 \mathrm{sec}$ の間を 4 通り，前進速度 (U) について 0.0〜1.2 m/sec の 5 通りとした。正弦 運動している場合，等価線形の考えから，

$$
\begin{aligned}
C_{d t} & =C_{d}+\frac{3 \pi}{8} \cdot \frac{U}{a \omega} \cdot C_{L \alpha} \\
& =C_{d}+\frac{3 \pi}{16} \cdot \frac{b}{a} \cdot \frac{1}{(\mathrm{~A} . \mathrm{R} .)} \cdot \frac{1}{k} C_{L \alpha}
\end{aligned}
$$

として $C_{d t}$ を定義すれば,（3）式は,

$$
\begin{aligned}
F= & -C_{m} \rho D a \omega^{2} \sin \omega t \\
& +\frac{4}{3 \pi} C_{d t} \rho S a^{2} \omega^{2} \cos \omega t
\end{aligned}
$$

と表わすことができる。一方，計測された周期的に変動 する流体力を

$$
F=-A \sin \omega t+B \cos \omega t
$$

と記述する時の係数 $A, B$ はフーリエ解析で求められる ので, 結局 $C_{m}, C_{d t}$ は,

$$
C_{m}=\frac{A-A^{\prime}}{\rho \bar{D} a \omega^{2}}-\frac{m}{\rho V}, \quad C_{d t}=\frac{3 \pi\left(B-B^{\prime}\right)}{4 S \rho a^{2} \omega^{2}}
$$

として求まる。ただし，本実験においては，平板翼のス パン中央を自由表面から $480 \mathrm{~mm}$ 没水させるために円断 面棒で支持しているので，あらかじめ支持棒のみに加わ る横力を計測した。 $A^{\prime}, B^{\prime}$ はこの時の流体力を(13) 式 で近似したときの係数であり, 同式中の $m$ は平板翼の質 量であり, Table 1 に示してある。

2）実験結果と計算值との比較

実験結果は, 全抗力係数 $C_{d t}$ - 付加質量係数 $C_{m}$ とも に, アスペクト比・振動振幅 $(a)$ と翼のスパン $(b)$ の比 $a / b$ ごとに整理し, reduced frequency の逆数 $(1 / k=2 U / \omega l)$ ベースにプロットした。これらのうち, $a / b=0.5,1.0$ の結果を, Fig. 9 から Fig. 12 に示す。

i ) 全抗力係数 $C_{C^{t} t}$

3 種類のアスペクト比の平板翼について，おのおの 5 種類の $a / b$ の実験を行なったが，そのうち $a / b=0.5$, 1.0 の実験值を Fig.9, Fig.10 に示す。(10) 式の $C_{L \alpha}$ を用いて (11) 式から求めた $C_{d t}$ を実線で示すっ図中下 部の鎖線は $C_{L \alpha}$ のみを表わしている。これらの図から わかるように, A.R. $=0.04$ の場合は, 計算值は比較的 良く実験値を説明するといえるが，A.R. $=0.06,0.08$ の場合には, $1 / k$ の增加により一度減少する傾向がある。 本論文には示さなかった $a / b$ の場合も考慮すると, 


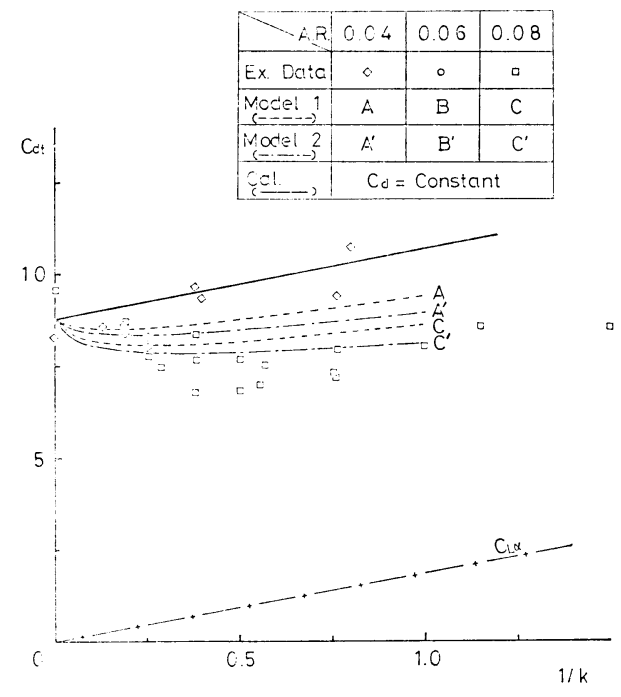

Fig. $9 C_{d t}$ vs. $1 / k$ Relations for $a / b=0.5$

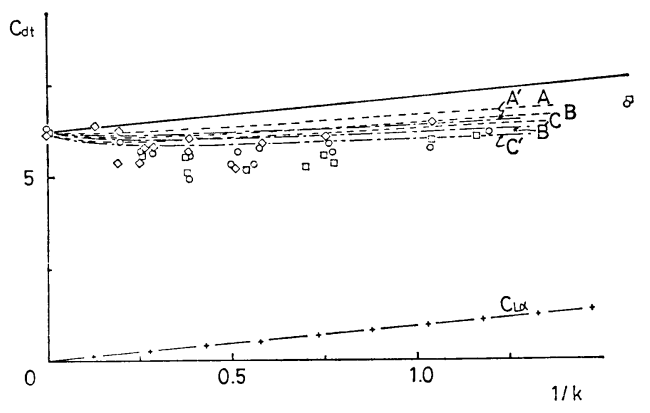

Fig.10 $C_{d t}$ vs. $1 / k$ Relations for $a / b=1.0$

この傾向は A.R. が大きいほど，また $a / b$ が小さいほ ど顕著であり，このことは，A.R. が大きくなるほど tip vortex の影響が小さくなるためと考えられ，U=0 での $C_{d}$ の值を用いたのでは抗力を過大に見積りすぎた むのと考えられる。また, 同時に $a / b$, すなわら振幅が 小さい時は定常運動をする翼では attack angle が小さ い場合に対応するので, tip vortex による非線形の効 果は小さくなると考えられる。

ii) 付加質量俰数 $C_{m}$

実験結果を Lawrence の方法による計算値とともに, Fig.11, Fig. 12 に示す。これらの図によれば, Lawrence の計算篗は昭らかに過小で，特に， $a / b$ が大きいほど両 者の差は大きく, さらに実駼值が明らかな $k$ によ依存 性を持つことを説明し得ない。しかし $C_{m}$ の值が $1 / k$ の 増加に伴い, 計算值に近ついてくることは, 振動平板の 前部で起った挸乱が後部におし流されてしまうために， 微小㹂乱を仮定した揚力面理論で考える流れ場に近づい てくるためと考えられる。

以上の柃討によれば，本侔文で考えた Lawrence の

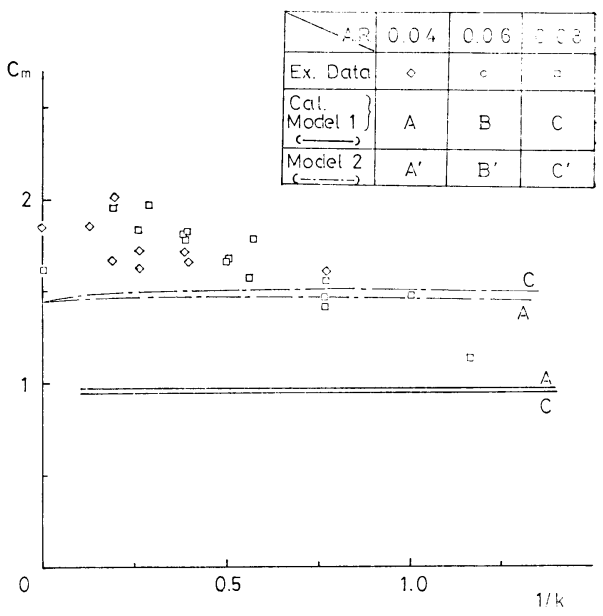

Fig, $11 C_{m}$ vs. $1 / k$ Relations for $a / b=0.5$

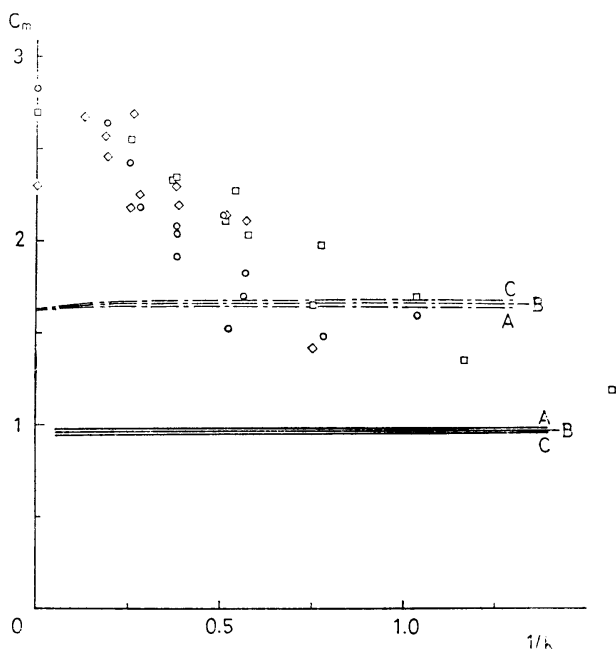

Fig. $12 C_{m}$ vs. $1 / k$ Relations for $a / b=1.0$

揚力面モデルと, Riabouchinsky の死水モデルを組み 合わせた流体モデルによる流体力のらち，速度成分につ いては計算值は実測値より大であり，加速度成分は計算 值の方が実測值より小となって，計算値と実測值の一致 度はあまりよくないことがわかった。そこで 5 章では， コード方向の圧力分布を調べることによって，上述の差 異についてさらに詳しく検討を加えることにする。

\section{5 コード方向圧力分布の計測実験}

アスペクト比 $0.08(l=1000 \mathrm{~mm}, b=80 \mathrm{~mm}, t=4 \mathrm{~mm})$ のアルミ製矩形翼の前縁から，40，310，850 mm の 3 箇所に圧力計 (ST 研究所製, PM-25-01: $P_{\mathrm{max}}=0.1$ $\left.\mathrm{kg} / \mathrm{cm}^{2}\right)$ を貼り付け，これを自由表面から $480 \mathrm{~mm}(6 b)$ 没水させ, 強制動摇させながら前進させて圧力変動を記 録した。この実験においては,ささら曳航電車を逆向き 
に走らせて計浿を行ない, 前縁から 150, $690,960 \mathrm{~mm}$ の位置に相当する個所の 圧力をも計測し，合わせてコード方向の 6 箇所の点で圧力を計測した。

次に解析に抢いては, 変動圧力が正圧 側・負圧側で，非対称となることと自由 表面に生ずる波による静的圧力の変化と を考慮し，兩面の美を如って変動圧 カとした。また, 変動匠力は, 速度成分 と加速度成分が分離できると仮定して, フーリエ解析法により求めた。

変動圧力を $\rho|\dot{z}|_{\max }^{2}$ で無次元化して 整理し，速度成分を Fig. 13 から Fig. 15 に，加速度成分を Fig.16から Fig.18に 示す。同図中の計算值は Lawrence の 方法によるものであるが, Lawrence の 方法では，医力分布として，スパン方向 に積分した値が求まるので，ここではス パン方向に棈円分布していると仮定して 計算したものである。速度成分について は, いずれのグラフの傾向もほぼ同一で ある。すなわち前進速度の増加に伴う前 縁での圧力差の增加およびそれ以外の部 分ではコード方向にあまり変化がないと いう結果となっている。次に，加速度成 分については，例光ば，Fig.17によれ ば，前縁付近から徐々に，揚力面による 計算值に近づく褋子がはっきり現われて いる。

これらのグラフから，前進速度の増加 に伴い, tip で㔀離した自由渦の影響が 前縁から徐々に少なくなって, 揚力面理 論で考光ていた流れ場に近づき，tip vortex に上る流体力の成分である抗力, すなわち $C_{d}$ の值は小さくなっていると 考えられよう。また， $C_{m}$ についても， この值が前進㥁度の増加に伴い計算值に 近つくことから， $C_{m}>1$ となる理由も tip vortex に市るのではないかと考えら れる。

以上を整理すると，次のような綕果が 得られる。

i ）圧力の速活成分は，前縁付近に おいて大となっている。なた, 前縁付近以外では, ニー ド方向にほぼ一定で, その值は $U=0$ の時の值よりも小 さくなっている。

ii）拄力の加速度成分は, 前進速度の増加に伴い,

$\frac{\Delta P_{1}}{\rho|\dot{z}|_{\max }^{2}}$
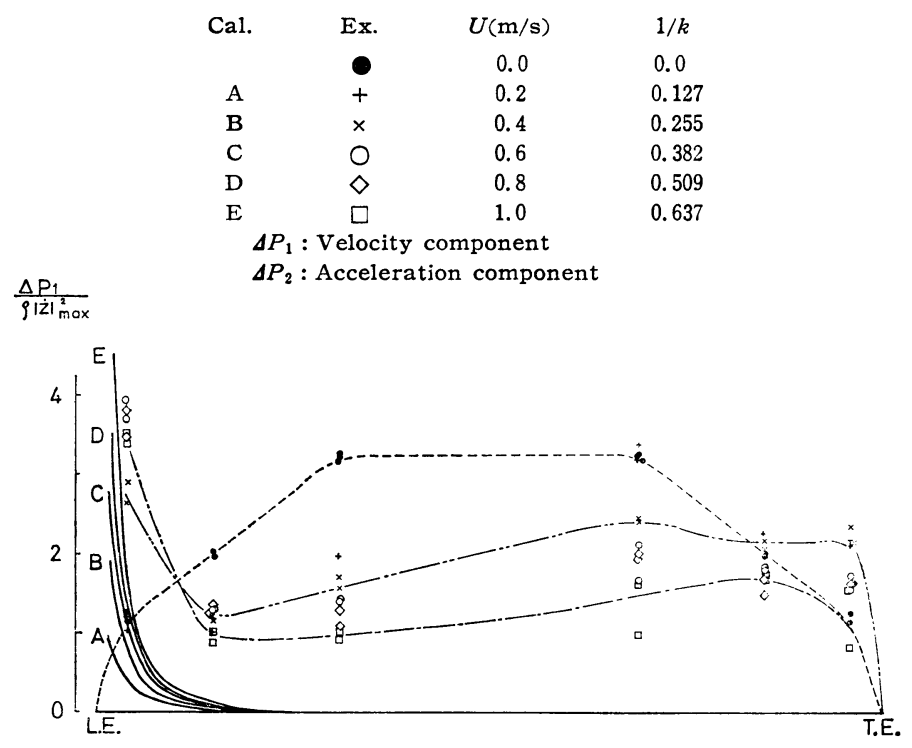

Fig. 13 Pressure Distribution for $a=0.06 \mathrm{~m}$ and $T=2.0 \mathrm{sec}$ (Velocity Component)

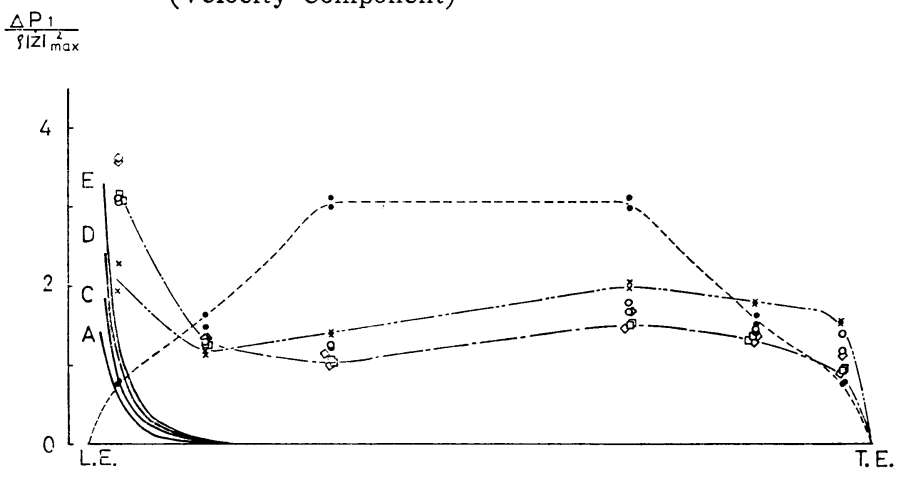

Fig. 14 Pressure Distribution for $a=0.08 \mathrm{~m}$ and $T=2.0 \mathrm{sec}$ (Velocity Component)

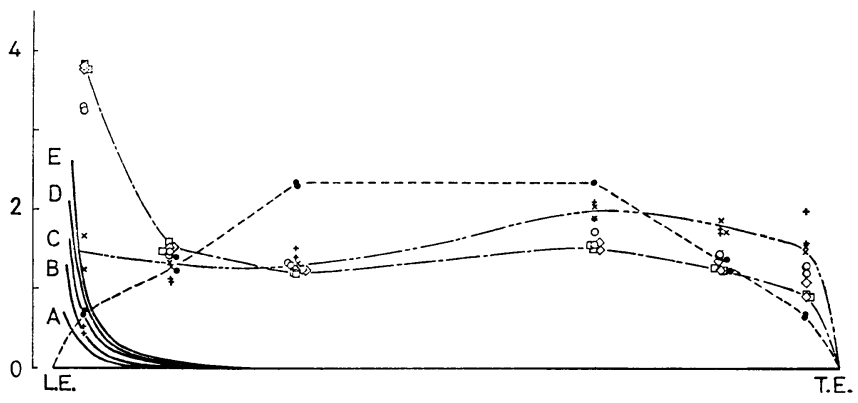

Fig. 15 Pressure Distribution for $a=0.10 \mathrm{~m}$ and $T=2.0 \mathrm{sec}$ (Velocity Component)

前縁付近から揚力面による計算値に近づく。

6 前進速度のある場合の死水領域について

Fig.9，Fig.10 に示したように, アスペクト比により 


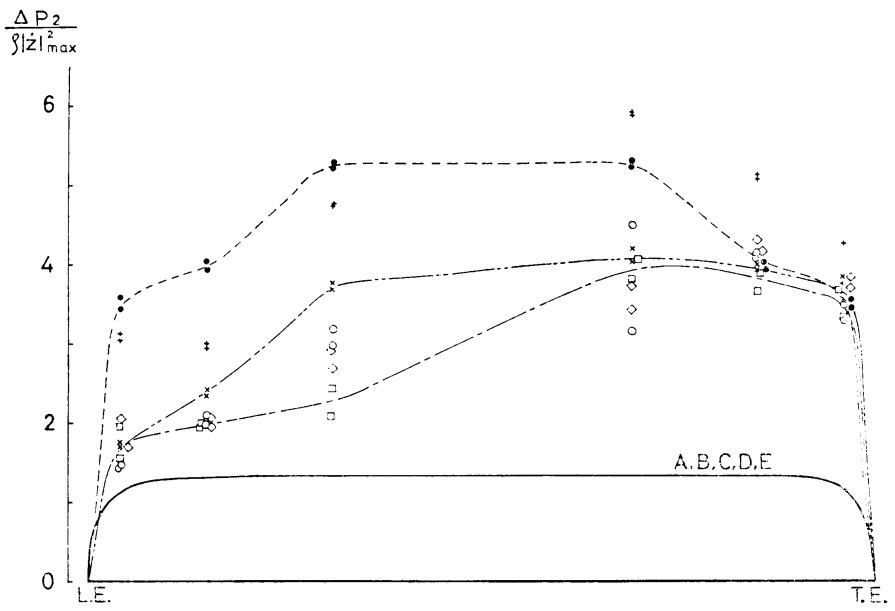

Fig. 16 Pressure Distribution for $a=0.06 \mathrm{~m}$ and $T=2.0 \mathrm{sec}$ (Acceleration Component)

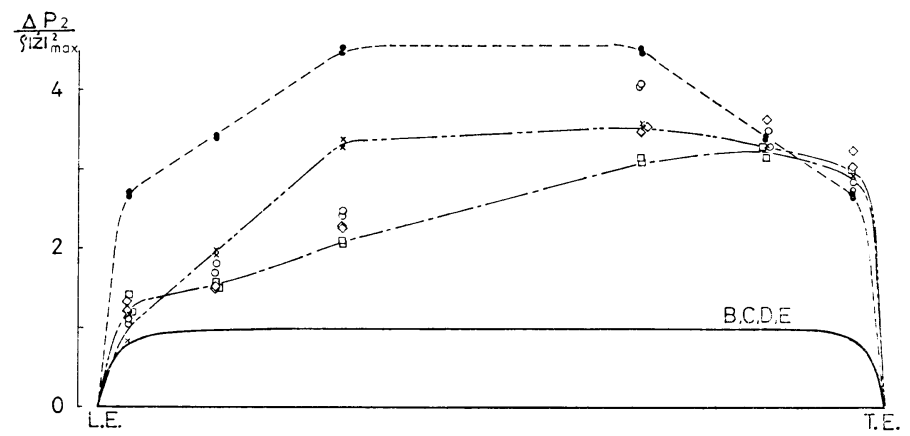

Fig. 17 Pressure Distribution for $a=0.08 \mathrm{~m}$ and $T=2.0 \mathrm{sec}$ (Acceleration Component)

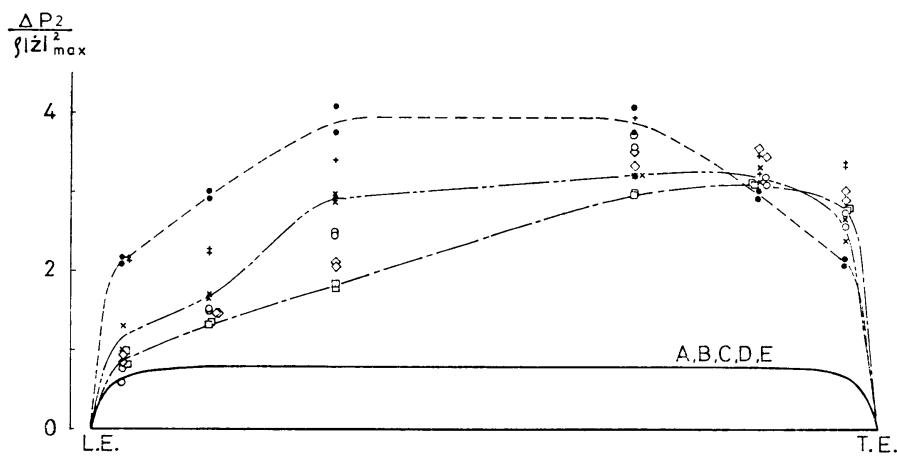

Fig. 18 Pressure Distribution for $a=0.1 \mathrm{~m}$ and $T=2.0 \mathrm{sec}$ (Acceleration Component)

多小程度の差はあっても, 前進速度の増加に伴い, $C_{d t}$ は一度減少してから増加する傾向であった， 5 章のコー ド方向圧力分布の実験結果から推測すると， $C_{d t}$ の減少 は $C_{d}$ の減少によるものと思われる。一方，揚力による 減衰成分は逆に増加していることが明らかになった。そ こで，圧力分布実験の結果を若干整理しなおして， $C_{d}$ の減少の様子および揚力の増加の様子を一定の $a / b$ につ いて, $1 / k$ (この無次元数は周期が一定ならば前進速度に
対応している) ベースでプロットしたの が Fig.19, Fig.20 である。ここで, Fig. 19 の上図には前縁から $40 \mathrm{~mm}$ の位 置での圧力の速度成分を $a / b=0.75$, 1.0，1.25 について示し, Lawrence の 方法による計算值を実線で示してある。 また，Fig.19の下図には，前縁から $690 \mathrm{~mm}$ の位置での圧力の速度成分を示 しており，Lawrence の方法による計算 值がほぼ 0 に等しいので，このグラフを 用いて $1 / k$ の增加に伴う $C_{d}$ の減少を説 明するための死水モデルを考えることに する。Fig. 20 は，上図，下図とも圧力 の加速度成分を示してあり，上図は前縁 から $690 \mathrm{~mm}$ ，下図は前縁から $40 \mathrm{~mm}$ での実験値で，実線は計算値である。

これらのグラフから，「圧力は，前進 速度の増加に伴い, 前縁付近から揚力面 理論による計算値に近づくが，圧力の計 算値に一様に近づくわ㚈ではない」とい うことがわかる。そこで, 前進速度の增 加に伴う $C_{d}$ の変化を考慮に入れた死水 モデルとして, 次の 2 つのモデルを考え て実験と比較してみた。モデルの概念図 を Fig. 21 に示す。

1)（死水モデル）+(揚力面理論モデ ル）の重ね合わせモデル

これは前述したモデルと同一である が，抗力係数 $C_{d}$ の前進速度による変化 を考慮に入れたものである。 $C_{d}$ の逗， すなわち死水領域の長さは A.R. $\cdot k \cdot a / b$ の 3 つの無次元変数により決定されると する。ところで,

i ) 横力実験 (Fig. 11, Fig. 12) か ら，アスペクト比が小さければ $C_{d}$ の減 少は小さくなる。

ii）前進速度 $U=0$ の時の横力実験 (Fig.2) から， $a / b$ については, (7) 式 に従って $C_{d}$ が変化する。

iii）圧力実験のらち, 前縁から $690 \mathrm{~mm}$ の位置での 速度成分の変化から，圧力の速度成分の $k$ に対する傾向

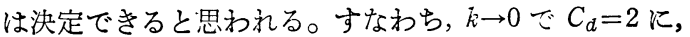
$k \rightarrow \infty$ で $C_{d}$ は $U=0$ の時の值にそれぞれ近づくもの と考えられる。

以上の i ）～iii）を考慮に入れて，

$$
\frac{h}{b}=\frac{H}{b}-\left(\frac{H}{b}-\frac{h_{0}}{b}\right) \frac{\sqrt{1+(1 / \text { A.R. })}}{\sqrt{1+(1 / \text { A. R. })+\sqrt{1 / k}}}
$$




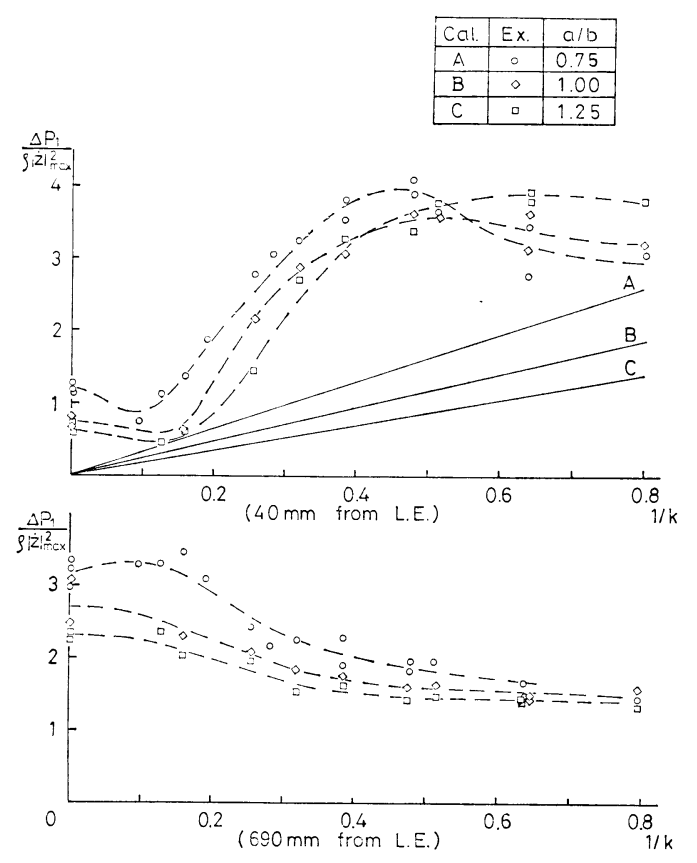

Fig. 19 Pressure vs. $1 / k$ Relations (Velocity Component)

と敒定する。ここで, $H / b$ は $C_{d}=2$ に相当する死水領 域の長さ, $h_{0} / b$ は $U=0$ での死水領域の長さとする。

2) 死水モデルのストリップ法的適用

1) のよらに（死水モデル)十(揚力面モデル) とは考 えず, 死水モデルで一貫して考えるもので, 死水域の長 さがコード方向に変化することを考慮する方法である。 すなわち各断面での流体力は, 仮定された死水域をるつ 平板の抗力と, 死水域の付いた平板の付加慣性力とから 成ると考えるもので，そのような断面の流体力をストリ ップ法的にコード方向に加え合わせることにより, 平板 全体に加わる流体力を算定する。

仮りに, 死水域の長さを $0<x<x_{0}$ の範囲に就いて, 次式のように $x$ 方向に放物線状に変わると仮定する。

$$
h / b=h_{0} / b \sqrt{\frac{x}{x_{0}}}
$$

ただし， $x_{0}=h_{0} / b \tan \beta$ となる。

位って, 平板の抗力係数 $C_{d t}^{*}$ は,

$$
\begin{aligned}
C_{d t}^{*} & =\frac{1}{l} \int_{0}^{l} C_{d} d x \\
& =\int_{0}^{1} C_{d} d x^{\prime} \quad\left(x^{\prime}=x / l\right) \\
& =\int_{0}^{x_{0}{ }^{\prime}} C_{d} d x^{\prime}+\left(1-x_{0}{ }^{\prime}\right) C_{d_{0}}
\end{aligned}
$$

と考える。ただし $C_{d_{0}}$ は一定死水領域（(15）式で与え るものとする) での $C_{d}$ で, $x_{0}$ 以降では死水領域が一 定と考えている。また， $C_{m}$ としては死水域の付いた 2

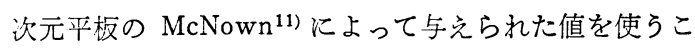

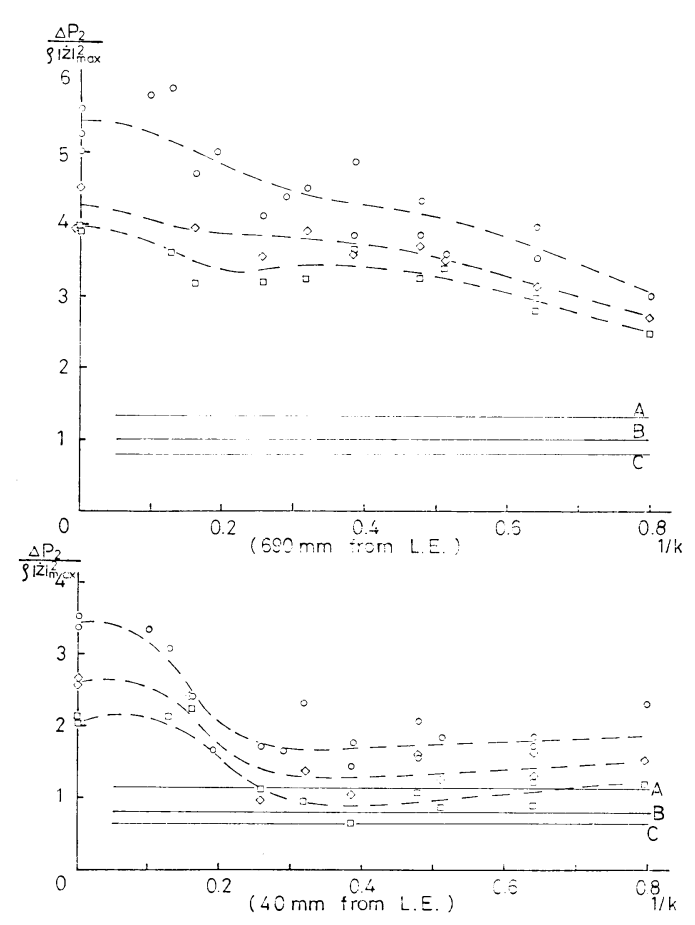

Fig. 20 Pressure vs. $1 / k$ Relations

(Acceleration Component)

1) Lithing surface theory with free strecm

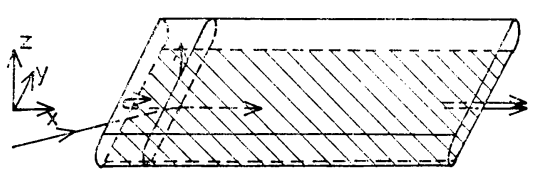

2) Strip method of free stream

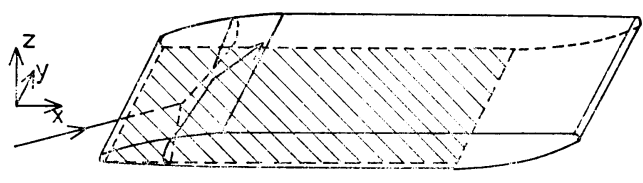

Fig. 21 Conception of Models

とにすれば, 平板の付加質量 $C_{m}^{*}$ は,

$$
C_{m}^{*}=\int_{0}^{1} C_{m} d x^{\prime}
$$

で与えられる。

以上，1），2）で計算した值を Fig.9〜Fig.12 にそれ ぞれ破線および鎖線で示す。この結果， $C_{d t}$ が $1 / k$ の増 加に伴って一時減少することをある程度説明できたが， $C_{m}$ の実測值の傾向はこのようなモデルを考えても十分 説明ができなかった。しかし, 振動平板翼の全流体力に 対する速度成分と加速度成分のそれぞれの寄与のうち, 
後者は一般にかなり小さいので, 速度成分について, こ の程度推定できれば実用上は満足すべきであろう。

\section{7 結 論}

小アスペクト比振動平板翼に関する基礎的研究とし て, 横力計湘実験・コード力向圧力分布計測実験を実施 すると同時に, 簡単な流体モデルによる流体力推定計算 を行ない，以下に示すような結論を得た。

1）次元解析の結果 振動平板翼に加わる流体力は, Reynolds 数 - reduced frequency $\cdot$ period parameter ・アスペクト比の 4 つの無次元変数により整理するのが 適切であるということが明らかになった。ただし，振動 平板に関するShih らの実験結果によれば, Reynolds 数が 250 以上であればその影響を考慮する必要はないと 考觉られる。

2） 2 次元振動平板作用する抗力は, 振動振幅 $a$ によって次式で決まる長さの死水をもつ平板に関する Riabouchinsky model でかなり良く説明できる。

$$
\frac{h}{b}=0.263 \frac{a}{b}+0.104
$$

3）微小㩭乱を仮定した Lawrence の方法に従った 計算で, 付加質量係数 $C_{m}$ ・揚力係数 $C_{L \alpha}$ はともに reduced frequencyによってはほとんど変化しないこ とがわかった。一方, 付加質量係数 $C_{m}$ の実験值は, か なり reduced frequency に依存しており，明らかに Lawrence のモデルには改良の必要がある。

4) $U=0$ での振動平板の抗力を説明する一定長さの 死水領域をもった “死水域を伴う揚力面理論モデル”で は, $C_{d t}$ が $1 / k$ の增加とともに一時減少することは説明 できない。コード方向圧力分布の計測実験によれば, $C_{d t}$ の $1 / k$ の増加に伴う減少は $C_{d}$ が $1 / k$ の増加とと もに減少することによるといえる。

5）前述の $C_{d t}$ の減少の傾向は, 死水域の長さを $k$, A.R., $a / b$ によって決定するものと仮定した（15）式を 用いればある程度説明でさた。

6）死水領域の決定, 付加質量係数の推定など, 今後 さらに検討を加党るべきことが多いとはいえ，本論文で 採用した “(死水) +(揚力面)”の重社合わせモデル, 拈 よび死水モデルのストリップ法的な適用は, 小アスペク ト比平板翼の非定常運勳時の簡単な流体力モデルとし て, 実用的価值があるといえる。ただし, 死水領域の決 定については今後研究を進めていく必要がある，

本研究は（社）日本造船研究協会第 161 研究部会によ る研究の一部として実施されたものであり, 部会長はじ め委員各位の有益な御教示, 御討議に対し, ここに厚く
御礼申し上げる。

また，実験にあたっては，東京大学工学部船舶工学科 運動性能研究室 伊田力助手々はじめとする職員各位 の多大な御助力を得た。ここに深く感謝の意を表する。

\section{参考文 献}

1) Y. Watanabe and S. Inoue : On the Property of Rolling Resistance of Ships and Its Calculation, 九州大学工学部紀要, 第 17 巻, (昭和 32 年）及び渡辺恵弘, 井上正祐: $N$ 係数計算法の 肥大船型への修正, 西部造船会会報, 第 27 号, (昭 和 38 年).

2) N. Tanaka : A Study on the Bilge Keel Part 1 Part 4, 造船協会論文集, 第 101 号; 103 号; 105 号; 109 号, (昭和 $32,33,34,36$ 年).

3) C.C. Shih and H. J. Buchanan: The Drag on Oscillating Flat Plates in Liquids at Low Reynolds Number, Jounal of Fluid Mechanics, Vol. 48, Part 2, pp. 229 239, Great Britain, 1971.

4）浜本剛実：小綎横比揚力面の積分方程式とその近 似解析, 日本造船学会論文集, 第 124 号, pp. 1 7 , (昭和 43 年 12 月).

5）野中晃二 : 三次元剥離を生じた小緃横比翼の計 算, 日本造船学会論文集, 第 135 号, pp. 63 89, (昭和 49 年 6 月).

6）貴島勝郎：Yawing しつつ前進する矩形板に働く 力の計算（渦の移動を考虑した場合）, 西部造船 学会報, 第 42 号, pp. 103 110, (昭和 47 年).

7) H. R. Lawrence : The Lift Distribution of Low-Aspect-Ratio Wings at Subsonic Speeds, JAS, Vol. 18, No.10, pp. 683 695, October, 1951.

8) V.L. Ed. Streeter : Handbook of Fluid Dynamics, 1st ed., McGrawhill Book Company, INC., New York, 1961.

9) D. Riabouchinsky : The Steady Fluid Motions with Free Surfaces, Pro. London Math. Soc., 19, pp. 206 215, 1920.

10) G. H. Keulegan and L. Carpenter : Forces on Cylinders and Plates in an Oscillating Fluid, Journal of Research of the National Bureau of Standards, Vol.60, No. 5, May, 1958.

11) J.S. McNown, Drag in Unsteady Flow, Proc. IX Int. Cong. Appl. Mech., Brussels, 1957.

12）池田良穂, 姫野洋司, 田中紀男：横摇礼淢衰力に ついて一一摩擦成分とビルジキールの直压力成分 一一関西造船学会誌, 第 161 号, pp. 41 49, (昭 和 51 年 6 月).

13) H.R. Lawrence and F.H. Gerber: The Aerodynamic Forces on Low Aspect Ratio Wings Oscillating in an In-compressible Flow, Journal of the Aeronautical Sciences, Vol. 19, No.11, pp.769 781, November, 1952. 